\title{
Low-altitude outbreaks of human fascioliasis related with summer rainfall in Gilan province, Iran
}

\author{
Abdoreza Salahi-Moghaddam¹, Majid Habibi-Nokhandam², Màrius V. Fuentes ${ }^{3}$ \\ ${ }^{1}$ Department of Parasitology, Hormozgan University of Medical Sciences, Bandar Abbas, Iran; ${ }^{2}$ Climatological \\ Research Institute, Mashhad, Iran; ${ }^{3}$ Departament de Parasitologia, Facultat de Farmàcia, Universitat de \\ València, Burjassot-València, Spain
}

\begin{abstract}
Following human fascioliasis outbreaks in 1988 and 1999 in Gilan province, northern Iran, efforts are now made to shed light on the seasonal pattern of fascioliasis transmission in this endemic area, taking into account snail host populations, climatic conditions and human cases. Populations of the intermediate host snail (Lymnaea spp.) peak in May and November, while there is a fourfold increase in the rate of human fascioliasis in February compared to that of September. Transmission is likely to occur mainly in late autumn and sporadically in late spring. Rainfall, seasonally analysed in periods of 3 years, indicates that accumulated summer rainfall may be related with the 1988 and 1999 human fascioliasis outbreaks. Although a more detailed picture, based on the analysis of further abiotic and biotic factors influencing fascioliasis transmission in this area, is required to substantiate this hypothesis, our results serve as the first step of a geographical information system project concerning the epidemiological study of fascioliasis in Iran. This local-scale study concerning the effects of climate change and natural disasters on the spread of fascioliasis aims to facilitate the understanding of what goes on at the regional scale in this respect.
\end{abstract}

Keywords: fascioliasis, human outbreak, summer rainfall, Iran.

Human fascioliasis is geographically widespread and recognised as a serious public health problem in some endemic areas, which includes the Andean countries in south America, northern Africa, areas in western Europe as well as Iran and some other Asian countries (Mas-Coma et al., 2005). The main problem with regard to fascioliasis in Iran is concentrated in the Gilan province on the Caspian Sea coast in the north, where high fascioliasis prevalence in livestock, caused by Fasciola hepatica and F. gigantica, has been documented many times since the 1960s. The first large outbreak of human fascioliasis in the north of Iran, in which more than 20,000 people were infected, was reported in 1988 (Assmar et al., 1991). Another outbreak with about 2,000 infected individuals occurred in 1999 (Rokni, 2008; Moghaddam, 2009). Follow-up studies show a relationship between stray cattle and the presence of lymnaeid snails (Moghaddam et al., 2004).

The affected area, Gilan province, is situated along the shores of the Caspian Sea (Fig. 1) reaching altitudes

Corresponding author:

Màrius V. Fuentes

Departament de Parasitologia, Facultat de Farmàcia,

Universitat de València, Avenida Vicent Andrés Estellés

46100 Burjassot-València, Spain

Tel. +3496354 42 98; Fax +3496354 4769

E-mail: mario.v.fuentes@uv.es

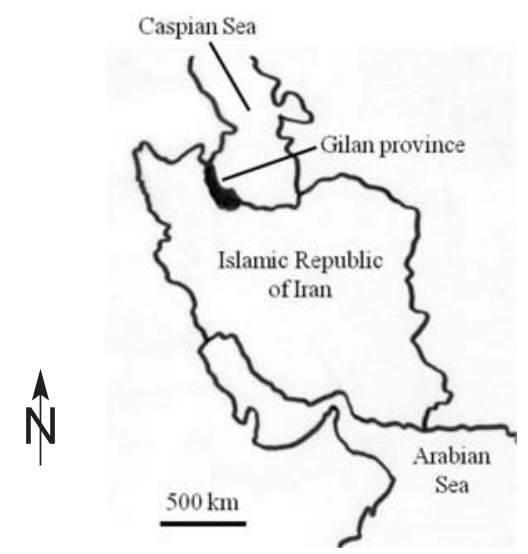

Fig. 1. Location of Gilan province in Iran.

between $15 \mathrm{~m}$ below sea level to $300 \mathrm{~m}$ above sea level, where $60 \%$ of the land-cover consists of wetlands, with numerous irrigation canals and rice cultivation as the main agricultural activity. The climate of the province, depicted in the climadiagram of the climate station of the town of Anzali (Fig. 2), is characterised by precipitation of 1300-1800 mm a year, an average temperature between 6.9 and $25.5(15.5-16.0){ }^{\circ} \mathrm{C}$, potential evapotranspiration (PET) between 15 and $133(62-65) \mathrm{mm}$, and a very short dry season in July but only in some parts of the province. Moreover, the normalized difference vegetation index (NDVI), obtained from AVHRR satellite images as proposed by Fuentes (2004), varies 


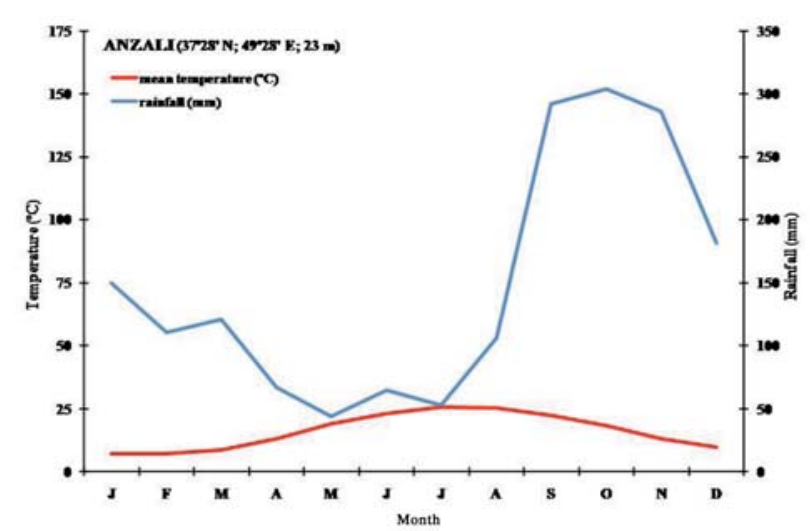

Fig. 2. Climadiagram for the climate station of Anzali.

between 0.35 and 0.44 in $98 \%$ of the total surface of the endemic area in the province (Fig. 3).

Research carried out in other endemic areas show that climatic factors, such as temperature, rainfall and potential evapotranspiration (the sum of evaporation and plant transpiration from the Earth's land surface to atmosphere), influence the population dynamics of the snail intermediate hosts and the free-living stages of Fasciola spp., mainly the metacercariae (Fuentes et al., 1999; Fuentes, 2006, 2007). Moreover, the role of a local dish called "delar", made from wild aquatic herbs which commonly harbour encysted Fasciola spp. metacercariae, has been documented, including the influence of climatic conditions on growth of these herbs (Ashrafi et al., 2006).

During the period from 1998 to 2002 human fascioliasis infections were reported from health centres in February and September, with a fourfold infection rate in February compared to September (Moghaddam et al., 2004). Transmission is likely to occur mainly in late autumn and sporadically in late spring, bearing in mind that the completion of the parasite's life cycle in the snail requires 3 months. Thus, the snail population in late summer constitutes an important factor in the epidemiology of fascioliasis in northern Iran, as summer climatic conditions influence the dynamics of the snail intermediate host population. Indeed, local studies concerning the snail intermediate host populations before the 1988 outbreak show that populations of Lymanea spp. had reached their peak in this area during the months of May and November (Moghaddam and Massoud, 2004).

A retrospective study of the climatic variables of epidemic years plus a comparative analysis with other years could be the key in understanding why and when human outbreaks occur. Therefore, we documented human fascioliasis outbreaks in Gilan province of the last 20 years with the aim of relating it with rainfall of that period. Rainfall data from 1980 to 2005 were obtained from the Iranian Meteorological Research Centre (Iranian National Meteorology Organisation), while data about epidemics and snails were obtained from local reports.

The 1988 and 1999 epidemics, and periods of 3 years in a row were considered as a group, as proposed by Fuentes (2007) for the analysis of fascioliasis transmission risk within the time frame of cyclic climatic events (such as the El Niño-Southern Oscillation). Each 3-year period starts with the following year, e.g. 1980-1982, 1981-1983, 1982-1984, ..., 2001-2003, 2002-2004, 2003-2005. Additionally, accumulated seasonal rainfall data was considered in the analysis of 24 3-year periods.

Data was arranged in SPSS version 13 for Windows (SPSS Inc, Chicago, IL, USA). The t-test was used to compare accumulated rainfall of each season between outbreak 3-year periods (1986-1988 and 1997-1999)
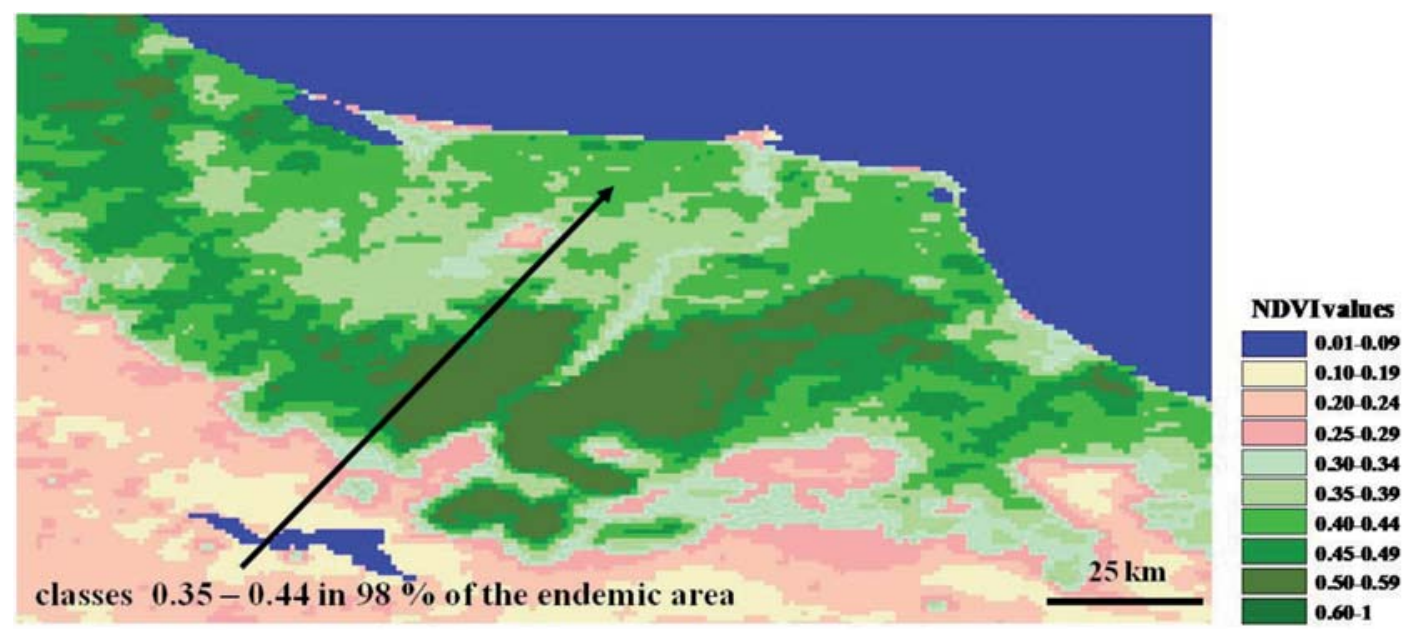

Fig. 3. Composite image of Gilan province (Iran) showing NDVI values. 
and the other 22 3-year periods. The statistical significance was established at the level of $\mathrm{P}<0.05$.

The analysis of the seasonal rainfall data indicated that only the years comprising 1987-1989, 1997-1999 and 2003-2004, and the 3-year periods of 1986-1988, 1987-1989, 1995-1997, 1996-1998, 1997-1999 and 1998-2000 presented an accumulated summer rainfall $>500 \mathrm{~mm}$ (Fig. 4). Moreover, the t-test showed that accumulated rainfall in summer during outbreak periods is higher than in other periods considered. This difference was statistically significant $(t=2.89 ; \mathrm{P}=0.009)$.

Slaughterhouse studies have shown higher infection rates in animals after the wet season (Pfukenyi and Mukaratirwa, 2004; Phiri et al., 2005), which characterises spring in the north of Iran (KuhsarJameshurani, 1995), whereas heavy rainfall in summer can be related with human outbreaks. The years of human fascioliasis outbreak (1988 and 1999) are at the end of both 3-year periods, which accumulated $>500 \mathrm{~mm}$ of rainfall for the complete period and for each individual year, respectively. After a climatic event, resulting in increased rainfall patterns, the healthcare sector ought to expect, and be prepared for, a sudden increase in the incidence of human fascioliasis in the following 2-year period as pointed out by Fuentes (2007). In the case of Gilan province, this climatic event could be three consecutive years with a rainfall $>500 \mathrm{~mm}$ in summer.

Undoubtedly, human fascioliasis outbreaks are influenced by other - well studied - abiotic and biotic factors, as expressed, for example, by NDVI and climatic forecast indices (Malone et al., 1998; Fuentes et al., 2005). In the case of Gilan province, climate, landcover and land use, as well as NDVI values, offer ideal conditions for snail development and fascioliasis transmission as previously demonstrated in other endemic areas (Fuentes, 2006).

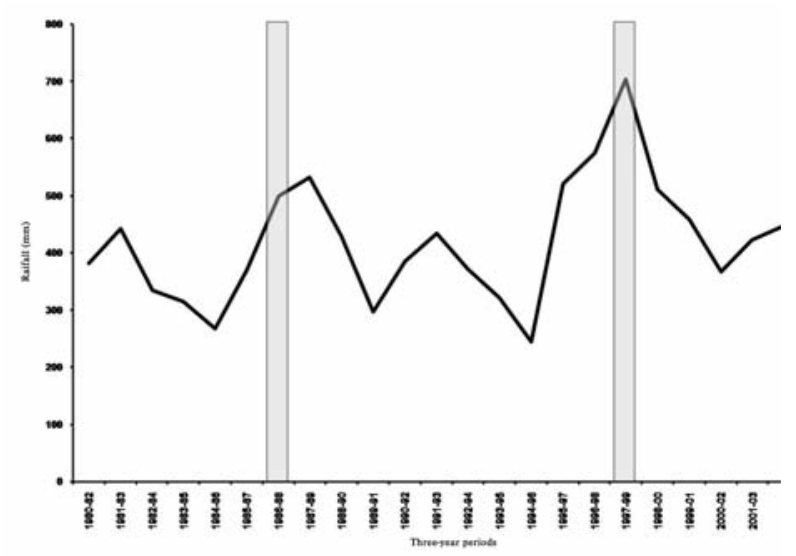

Fig. 4. Accumulated summer rainfall in the 3-year periods studied. Bars show human fascioliasis outbreaks in 1988 and 1999.
Future studies on human and animal fascioliasis in northern Iran should focus, as previously proposed for other endemic regions, on the creation of a geographical information system project, including existing and new epidemiological data as well as additional climatic and new remote sensing data (Fuentes, 2006). Therefore, the first step of this project would be the analysis of the influence of summer rainfall on patterns of human fascioliasis outbreaks in Gilan province. Although our results are preliminary and currently merely of local interest, local-scale studies of this kind should improve understanding of regionalscale studies as well as research on the effects of climate change and natural disasters.

\section{Acknowledgements}

This research was funded by the Climatological Research Institute, Mashhad, Iran.

\section{References}

Ashrafi K, Valero MA, Massoud J, Sobhani A, SolaymaniMohammadi S, Conde P, Khoubbane M, Bargues MD, MasComa S, 2006. Plant-borne human contamination by fascioliasis. Am J Trop Med Hyg 75, 295-302.

Assmar M, Milaninia A, Amirkhani A, Yadegari D, ForghanParast K, Nahravanian H, Piazak N, Esmayli A, Hovanesian A, Valadkhani Z, 1991. Seroepidemiological investigation of fascioliasis in northern Iran. Med J Iran 5, 23-27.

Fuentes MV, 2004. Proposal of a geographic information system for modeling zoonotic fascioliasis transmission in the Andes. Parasitol Latinoam 59, 51-55.

Fuentes MV, 2006. Remote sensing and climate data as a key for understanding fasciolosis transmission in the Andes: review and update of an ongoing interdisciplinary project. Geospat Health 1, 59-70.

Fuentes MV, 2007. Is the El Niño-Southern Oscillation likely to increase the risk of Fasciola transmission? Ann Trop Med Parasitol 101, 555-557.

Fuentes MV, Sainz-Elipe S, Nieto P, Malone JB, Mas-Coma S, 2005. Geographical information systems risk assessment models for zoonotic fasciolosis in the South American Andes region. Parassitologia 47, 151-156.

Fuentes MV, Valero MA, Bargues MD, Esteban JG, Anglés R, Mas-Coma S, 1999. Analysis of climatic data and forecast indices for human fascioliasis at very high altitude. Ann Trop Med Parasitol 93, 835-850.

Kuhsar-Jameshurani F, 1995. Prevalence of helminthiasis (Fasciola, Dicrocoelium, hydatidic cyst) in slaughtered cattle in Gonbad Kavus district. MS thesis, Tehran Univ Med Sci, Iran. 
Malone JB, Gommes R, Hansen J, Yilma JM, Slingenberg J, Snijders F, Nachtergaele F, Ataman E, 1998. A geographic information system on the potential distribution and abundance of Fasciola hepatica and F. gigantica in East Africa based on Food and Agriculture Organization databases. Vet Parasitol 78, 87-101.

Mas-Coma S, Bargues MD, Valero MA, 2005. Fascioliasis and other plant-borne trematode zoonoses. Int J Parasitol 35, 1255-1278.

Moghaddam AS, 2009. Epidemiology of human fascioliasis in Iran. J Kerman Univ Med Sci 16, 385-398.

Moghaddam AS, Massoud J, 2004. Descriptive study of fascioliasis in Mazandaran province from seasonal transmission point of view. Hormozgan Med J 8, 145-149.
Moghaddam AS, Massoud J, Mahmoodi M, Mahvi AH, Periago MV, Artigas P, Fuentes MV, Bargues MD, Mas-Coma S, 2004. Human and animal fascioliasis in Mazandaran province northern Iran. Parasitol Res 94, 61-69.

Pfukenyi DM, Mukaratirwa S, 2004. A retrospective study of the prevalence and seasonal variation of Fasciola gigantica in cattle slaughtered in the major abattoirs of Zimbabwe between 1990 and 1999. Onderstepoort J Vet Res 71, 181-187.

Phiri AM, Phiri IK, Siziya S, Sikasunge CS, Chembensofu M, Monrad J, 2005. Seasonal pattern of bovine fasciolosis in the Kafue and Zambezi catchment areas of Zambia. Vet Parasitol 134, 87-92.

Rokni MB, 2008. The present status of human helminthic diseases in Iran. Ann Trop Med Parasitol 102, 283-295. 